\title{
Zika Virus on YouTube: An Analysis of English-language Video Content by Source
}

\author{
Corey H. Basch ${ }^{1 *}$, Isaac Chun-Hai Fung ${ }^{2 *}$, Rodney N. Hammond ${ }^{1}$, Elizabeth B. Blankenship ${ }^{2}$, Zion Tsz Ho Tse ${ }^{3}$, King-Wa Fu ${ }^{4}$ \\ Patrick Ip ${ }^{5}$, Charles E. Basch ${ }^{6}$ \\ ${ }^{1}$ Department of Public Health, William Paterson University College of Science and Health, Wayne, NJ; '² Department of Epidemiology and \\ Environmental Health Sciences, Jiann-Ping Hsu College of Public Health, Georgia Southern University, Statesboro, GA; ${ }^{3}$ College of Engineering, \\ The University of Georgia, Athens, GA, USA; ${ }^{4}$ Journalism and Media Studies Centre, The University of Hong Kong, Hong Kong; ${ }^{5}$ Department of Pedi- \\ atrics and Adolescent Medicine, Li Ka Shing Faculty of Medicine, The University of Hong Kong, Hong Kong; ${ }^{6}$ Department of Health and Behavior \\ Studies, Teachers College, Columbia University, New York, NY, USA
}

Objectives: The purpose of this study was to describe the source, length, number of views, and content of the most widely viewed Zika virus (ZIKV)-related YouTube videos. We hypothesized that ZIKV-related videos uploaded by different sources contained different content.

Methods: The 100 most viewed English ZIKV-related videos were manually coded and analyzed statistically.

Results: Among the 100 videos, there were 43 consumer-generated videos, 38 Internet-based news videos, 15 TV-based news videos, and 4 professional videos. Internet news sources captured over two-thirds of the total of 8894505 views. Compared with consumergenerated videos, Internet-based news videos were more likely to mention the impact of ZIKV on babies (odds ratio [OR], 6.25; 95\% confidence interval $[\mathrm{Cl}], 1.64$ to 23.76), the number of cases in Latin America (OR, 5.63; 95\% Cl, 1.47 to 21.52); and ZIKV in Africa (OR, 2.56; $95 \% \mathrm{Cl}, 1.04$ to 6.31 ). Compared with consumer-generated videos, TV-based news videos were more likely to express anxiety or fear of catching ZIKV (OR, 6.67; 95\% Cl, 1.36 to 32.70); to highlight fear of ZIKV among members of the public (OR, 7.45; $95 \% \mathrm{Cl}, 1.20$ to 46.16$)$; and to discuss avoiding pregnancy $(\mathrm{OR}, 3.88 ; 95 \% \mathrm{Cl}, 1.13$ to 13.25$)$.

Conclusions: Public health agencies should establish a larger presence on YouTube to reach more people with evidence-based information about ZIKV.

Key words: Zika virus, Health communication, Internet, Social media

Received: November 7, 2016 Accepted: January 18, 2017

Corresponding author: Isaac Chun-Hai Fung, PhD

P.0. Box 8015, Statesboro, GA 30460-8015, USA

Tel: +1-912-478-5079, Fax: +1-912-478-0171

E-mail: cfung@georgiasouthern.edu

*Basch \& Fung have contributed equally to this work as joint first authors.

This is an Open Access article distributed under the terms of the Creative Commons Attribution Non-Commercial License (http://creativecommons.org/licenses/by$\mathrm{nc} / 4.0 /$ ) which permits unrestricted non-commercial use, distribution, and reproduction in any medium, provided the original work is properly cited.

\section{INTRODUCTION}

Zika virus (ZIKV) is known to cause microcephaly among some neonates born to ZIKV-infected women and is associated with the onset of Guillain-Barré syndrome among some infected patients $[1,2]$. As no vaccine or treatment is available, health communication has become a key intervention, as well as mosquito control.

Social media is an emerging tool for health communication during outbreak responses [3]. Recent research on ZIKV-related 
social media health communication has focused on Twitter [4-6] and Facebook [7]. Previous research has highlighted the importance of visual images in health communication [8]. Accounting for $22 \%$ of social media traffic, YouTube is the second most popular social media site in the US [9]. Previous studies found that YouTube videos about outbreaks can attract thousands, even millions, of views, but many of these videos are created and uploaded by non-professionals [10]. News videos uploaded online draw considerable attention from social media users and stimulate traffic between sites. For example, a study suggested that Ebola-related online videos released by two major news channels drove up Ebola-related Twitter traffic in 2014 [11].

While health agencies endeavor to communicate a core set of messages about infectious diseases to the public, people also acquire health information from non-professional sources, including videos posted by consumers, which sometimes contain content that is inconsistent with the best available scientific evidence [12]. This runs the risk of confusing the general public and undermining the effectiveness of public health communication campaigns. Content analysis of YouTube videos provides public health professionals with an overview of the information that the populations they serve are most likely to receive.

We present a cross-sectional study of English language ZIKVrelated YouTube videos in which their source, length, number of views, and content were manually coded. Our hypothesis was that ZIKV-related YouTube videos created and uploaded by different sources contained different content. More specifically, the content of Internet-based news videos, TV-based news videos, and videos created by medical professionals or government agencies was hypothesized to be different from that of videos uploaded by individual lay consumers.

\section{METHODS}

\section{Data Retrieval}

We searched for "Zika virus" on www.youtube.com with the default content location (US). Popularity was determined by the total view count, which was determined by sorting videos according to how many times they had been viewed. In order to reach the study goal of watching the 100 most popular videos, a total of 253 videos were viewed; 153 videos were excluded because they were not in English. One of the primary sources of information used to create categories was the main ZIKV webpage from the Centers for Disease Control and Prevention [13]. At the time the categories were made, information on the page was last reviewed on February 11, 2016, and all updates through March 14, 2016 were included. A sample of 15 videos that were not included in the sample of 100 videos due to low viewership was used to inductively generate additional content categories. Categories for the source, length, and date that the video was uploaded were also parts of the coding instrument.

\section{Manual Coding}

One author coded the entire sample of 100 videos. First, the source of the uploaded video was determined. Consumer videos were delineated as those posted by a member of the lay public. Professional videos were those posted by an individual with the qualifications to be working in a medical profession. Network television was distinguished as shows that were focused on entertainment, whereas TV-based news clips were focused on providing news and information to the viewer. Internet-based news was considered the provision of news and information on a website that was not affiliated with a television station. A government source was defined as anything with a tag from a government agency. Finally, print or radio sources were videos created by a conventional print or radio source. For each video, the following information was documented: its source, its year uploaded, its length in minutes, and its total number of views as of May 9, 2016.

Content categories were coded dichotomously as 'yes' or 'no' depending on whether the topic of each category was mentioned: general and specific modes of disease transmission (mosquito, male sex partner, transfusion, other avenues); impact on infants; ZIKV treatment; anxiety and fear of catching ZIKV; modes of prevention; number of cases overall, in Latin America, and in the US; public fear of ZIKV; avoiding pregnancy; lack of preparedness in the US; highlights of specific ZIKV cases in the US; need for financial aid to non-US countries; need for medical help/medical resources in Latin America; need for the US to allocate additional funds for disaster preparedness; need for international cooperation/response; need for training of healthcare personnel; need for coordination between local, state, and federal governments; danger for healthcare personnel; Olympics in Brazil; ZIKV as a hoax, as intentional population control, or other conspiracy theories; and whether the video was part of a comedy skit/parody or prank about ZIKV.

To confirm inter-rater reliability, 15 of the 100 video samples were randomly chosen and double-coded by a second researcher. There was 100\% agreement between two coders for all content variables. The two coders agreed on the category 
of the source for 14 of the 15 videos, and the single disagreement was resolved by consensus.

\section{Statistical Analysis}

Analysis was conducted in R 3.3.0 (https://www.r-project. org/). For the sources of videos, we merged the 'government' category $(n=3)$ and the 'professional' category $(n=1)$ into a combined 'professional' category $(n=4)$. For the length of videos, given that the distribution was not normal, we performed the Kruskal-Wallis $\mathrm{H}$-test across the four source categories and Wilcoxon rank sum test between the categories in a pairwise manner. We performed univariate logistic regression with the source of the video as the predictor variable and the manually coded content variables as outcome variables. We calculated the odds ratio $(\mathrm{OR})$ of a specific type of video (professional, Internet-based news, and TV-based news) showing a specific type of content as compared with the reference category (consumers' videos).

\section{Ethical Approval}

This study was determined not to be human subject research by the institutional review board of William Paterson University.

\section{RESULTS}

Among the 100 manually coded ZIKV-related YouTube videos, there were 43 consumer-generated videos, 38 Internetbased news videos, 15 TV-based news videos and 4 professional videos (Table 1). Collectively, these videos were viewed 8894505 times. Internet-based news videos and consumer videos accounted for 67.7 and $22.4 \%$ of the total 8894505 views, respectively. The distribution of video length was significantly different across the four source categories (KruskalWallis $\chi^{2}=12.215, p=0.007$ ). Pairwise comparison found statistically significant differences between consumer-generated videos and TV-based news videos ( $\mathrm{W}=511, p<0.001)$ and between TV-based news videos and Internet-based news videos $(W=175, p<0.05)$. Likewise, the distribution of the number of views was significantly different across the four source categories (Kruskal-Wallis $\chi^{2}=9.473, p<0.05$ ). Pairwise comparison found a statistically significant difference between consumergenerated videos and Internet-based news videos ( $W=529$, $p=0.006$ ). Across the 100 videos, a small positive correlation existed between the length of the video and the number of views of the video (Spearman rho $=0.24 ; S=127160 ; p<0.05$ ).

Table 2 presents the frequency of ZIKV-related YouTube videos by their content and source categories. ORs for each content category to be covered according to the source, using consumer-generated videos as a reference category, are presented in Table 3. Compared with consumer-generated videos, Internet-based news videos were 6.25 times more likely to mention the impact of ZIKV impact on babies $(95 \% \mathrm{Cl}, 1.64$ to 23.76), 5.63 times more likely to mention the number of cases in Latin America ( $95 \% \mathrm{Cl}, 1.47$ to 21.52); and 2.56 times more likely to mention ZIKV in Africa ( $95 \% \mathrm{Cl}, 1.04$ to 6.31 ). In contrast, compared with consumer-generated videos, TV-based news videos were 6.67 times more likely to express anxiety or fear of catching ZIKV ( $95 \% \mathrm{Cl}, 1.36$ to 32.70), 7.45 times more likely to highlight fear of ZIKV among members of the public ( $95 \% \mathrm{Cl}, 1.20$ to 46.16$)$, and 3.88 times more likely to discuss not becoming pregnant $(95 \% \mathrm{Cl}, 1.13$ to 13.25$)$. Professional videos were much more likely to highlight ZIKV cases in the US (OR, 20.50; $95 \% \mathrm{Cl}, 1.82$ to 230.51$)$ than consumer-generated videos, but there was a very small sample of professional videos $(n=4)$, representing only $1.3 \%$ of total views.

\section{DISCUSSION}

This cross-sectional study categorized the information circulated by the 100 most popular ZIKV-related YouTube videos in English, as well as their respective sources. Of the 100 videos,

Table 1. Length and number of views of the 100 most popular English-language ZIKV-related videos posted on YouTube

\begin{tabular}{|c|c|c|c|c|c|c|c|c|c|c|}
\hline & \multirow{2}{*}{ n } & \multicolumn{4}{|c|}{ Video length (min) } & \multicolumn{5}{|c|}{ No. of views } \\
\hline & & Mean [SE] & Median & Range & $95 \% \mathrm{CI}$ & Mean [SE] & Median & Range & $95 \% \mathrm{Cl}$ & Total (\%) \\
\hline Consumer & 43 & $7.62[1.06]$ & 5.82 & $0.15-37.25$ & $5.49,9.76$ & 46311 [7453] & 26260 & $11910-216700$ & 31269,61352 & 1991358 (22.4) \\
\hline Internet-based news & 38 & $6.77[1.10]$ & 4.83 & $0.87-28.12$ & $4.55,8.99$ & 158500 [39886] & 51680 & $12300-1224000$ & 77684,239317 & 6023012 (67.7) \\
\hline Professional & 4 & $3.27[0.38]$ & 3.36 & $2.40-3.95$ & $2.06,4.47$ & 28821 [10483] & 22200 & $11600-59290$ & $-4540,62182$ & $115284(1.3)$ \\
\hline TV-based news & 15 & $3.19[0.66]$ & 2.27 & $1.40-10.32$ & $1.77,4.61$ & 50990 [16344] & 24120 & 12 230-264 400 & 15936,86044 & 764851 (8.6) \\
\hline Overall & 100 & $6.46[0.64]$ & 4.58 & $0.15-37.25$ & $5.19,7.73$ & 88945 [16492] & 31120 & $11600-1224000$ & 56222,121668 & 8894505 (100.0) \\
\hline
\end{tabular}

ZiKV, Zika virus; SE, standard error; Cl, confidence interval. 
Table 2. Frequency count of 100 Zika virus-related videos in English by their source and content

\begin{tabular}{|c|c|c|c|c|c|}
\hline \multirow[b]{2}{*}{ Content category ${ }^{1}$} & \multicolumn{5}{|c|}{ Source category of videos } \\
\hline & $\begin{array}{c}\text { Consumer } \\
(n=43)\end{array}$ & $\begin{array}{l}\text { Internet-based } \\
\text { news ( } \mathbf{n}=\mathbf{3 8})\end{array}$ & $\begin{array}{l}\text { Professional } \\
\quad(n=4)\end{array}$ & $\begin{array}{c}\text { TV-based news } \\
\quad(n=15)\end{array}$ & $\begin{array}{c}\text { Total } \\
(n=100)\end{array}$ \\
\hline \multicolumn{6}{|c|}{ Transmission: mentioned how Zika is transmitted } \\
\hline No & $9(21)$ & $4(11)$ & $0(0)$ & $0(0)$ & $13(13)$ \\
\hline Yes & $34(79)$ & $34(89)$ & $4(100)$ & $15(100)$ & $87(87)$ \\
\hline \multicolumn{6}{|c|}{ Mosquito: mentioned that Zika is transmitted by mosquitos } \\
\hline No & $9(21)$ & $4(11)$ & $0(0)$ & $0(0)$ & $13(13)$ \\
\hline Yes & $34(79)$ & $34(89)$ & $4(100)$ & $15(100)$ & $87(87)$ \\
\hline \multicolumn{6}{|c|}{ Sex: mentioned Zika transmission through male sex partners } \\
\hline No & $27(63)$ & $25(66)$ & $3(75)$ & $11(73)$ & $66(66)$ \\
\hline Yes & $16(37)$ & $13(34)$ & $1(25)$ & $4(27)$ & $34(34)$ \\
\hline \multicolumn{6}{|c|}{ Transfusion: mentioned Zika transmission through transfusion } \\
\hline No & $41(95)$ & $37(97)$ & $4(100)$ & $15(100)$ & $97(97)$ \\
\hline Yes & $2(5)$ & $1(3)$ & $0(0)$ & $0(0)$ & $3(3)$ \\
\hline \multicolumn{6}{|c|}{ Baby: mentioned the impact of Zika on babies } \\
\hline No & $15(35)$ & $3(8)$ & $0(0)$ & $0(0)$ & $18(18)$ \\
\hline Yes & $28(65)$ & $35(92)$ & $4(100)$ & $15(100)$ & $82(82)$ \\
\hline \multicolumn{6}{|c|}{ Treatment: mentioned treatment of Zika } \\
\hline No & $43(100)$ & $37(97)$ & $4(100)$ & $15(100)$ & $99(99)$ \\
\hline Yes & $0(0)$ & $1(3)$ & $0(0)$ & $0(0)$ & $1(1)$ \\
\hline \multicolumn{6}{|c|}{ Anxiety: mentioned anxiety/fear of catching Zika } \\
\hline No & $40(93)$ & $33(87)$ & $3(75)$ & $10(67)$ & $86(86)$ \\
\hline Yes & $3(7)$ & $5(13)$ & $1(25)$ & $5(33)$ & $14(14)$ \\
\hline \multicolumn{6}{|c|}{ Prevention: mentioned (any) prevention } \\
\hline No & $29(67)$ & $31(82)$ & $0(0)$ & $6(40)$ & $66(66)$ \\
\hline Yes & $14(33)$ & $7(18)$ & $4(100)$ & $9(60)$ & $34(34)$ \\
\hline \multicolumn{6}{|c|}{ Case: mentioned number of cases } \\
\hline No & $38(88)$ & $30(79)$ & $3(75)$ & $10(67)$ & $81(81)$ \\
\hline Yes & $5(12)$ & $8(21)$ & $1(25)$ & $5(33)$ & $19(19)$ \\
\hline \multicolumn{6}{|c|}{ Latin America: mentioned number of cases in Latin America } \\
\hline No & $14(33)$ & $3(8)$ & $0(0)$ & $0(0)$ & $17(17)$ \\
\hline Yes & $29(67)$ & $35(92)$ & $4(100)$ & $15(100)$ & $83(83)$ \\
\hline \multicolumn{6}{|c|}{ US: mentioned number of cases in the US } \\
\hline No & $35(81)$ & $31(82)$ & $2(50)$ & $10(67)$ & $78(78)$ \\
\hline Yes & $8(19)$ & $7(18)$ & $2(50)$ & $5(33)$ & $22(22)$ \\
\hline \multicolumn{6}{|c|}{ Public fear: highlighted that the public is/was afraid } \\
\hline No & $41(95)$ & $37(97)$ & $4(100)$ & $11(73)$ & $93(93)$ \\
\hline Yes & $2(5)$ & $1(3)$ & $0(0)$ & $4(27)$ & $7(7)$ \\
\hline \multicolumn{6}{|c|}{ Not pregnant: discussed not becoming pregnant } \\
\hline No & $31(72)$ & $21(55)$ & $4(100)$ & $6(40)$ & $62(62)$ \\
\hline Yes & $12(28)$ & $17(45)$ & $0(0)$ & $9(60)$ & $38(38)$ \\
\hline \multicolumn{6}{|c|}{ US cases: highlighted cases in the US } \\
\hline No & 41 (95) & 36 (95) & $2(50)$ & $12(80)$ & 91 (91) \\
\hline Yes & 2 (5) & 2 (5) & $2(50)$ & $3(20)$ & $9(9)$ \\
\hline \multicolumn{6}{|c|}{ Olympics: discussed the 2016 Olympics in Brazil } \\
\hline No & 38 (88) & 30 (79) & $4(100)$ & $13(87)$ & $85(85)$ \\
\hline Yes & $5(12)$ & $8(21)$ & $0(0)$ & $2(13)$ & $15(15)$ \\
\hline
\end{tabular}


Table 2. Continued from the previous page

\begin{tabular}{|c|c|c|c|c|c|}
\hline \multirow[b]{2}{*}{ Content category ${ }^{1}$} & \multicolumn{5}{|c|}{ Source category of videos } \\
\hline & $\begin{array}{c}\text { Consumer } \\
(n=43)\end{array}$ & $\begin{array}{l}\text { Internet-based } \\
\text { news ( } \mathbf{n}=\mathbf{3 8})\end{array}$ & $\begin{array}{l}\text { Professional } \\
\quad(n=4)\end{array}$ & $\begin{array}{l}\text { TV-based news } \\
\quad(n=15)\end{array}$ & $\begin{array}{c}\text { Total } \\
(\mathbf{n}=100)\end{array}$ \\
\hline \multicolumn{6}{|c|}{$\begin{array}{l}\text { Hoax: mentioned that people felt that Zika is a hoax, there is } \\
\text { no such thing, or cases are staged }\end{array}$} \\
\hline No & $40(93)$ & $33(87)$ & $4(100)$ & $15(100)$ & $92(92)$ \\
\hline Yes & $3(7)$ & $5(13)$ & $0(0)$ & $0(0)$ & $8(8)$ \\
\hline \multicolumn{6}{|c|}{$\begin{array}{l}\text { Conspiracy: mentioned Zika as being intentional, population } \\
\text { control, conspiracy theory, etc. }\end{array}$} \\
\hline No & $31(72)$ & $27(71)$ & $4(100)$ & $15(100)$ & $77(77)$ \\
\hline Yes & $12(28)$ & $11(29)$ & $0(0)$ & $0(0)$ & $23(23)$ \\
\hline \multicolumn{6}{|c|}{ Comedy: part of a comedy skit/parody } \\
\hline No & $42(98)$ & $38(100)$ & $4(100)$ & $15(100)$ & $99(99)$ \\
\hline Yes & $1(2)$ & $0(0)$ & $0(0)$ & $0(0)$ & $1(1)$ \\
\hline \multicolumn{6}{|c|}{ Prank: pranking somebody about Zika } \\
\hline No & $42(98)$ & $38(100)$ & $4(100)$ & $15(100)$ & $99(99)$ \\
\hline Yes & $1(2)$ & $0(0)$ & $0(0)$ & $0(0)$ & $1(1)$ \\
\hline \multicolumn{6}{|c|}{ Africa: mentioned Zika in Africa } \\
\hline No & $29(67)$ & $17(45)$ & $4(100)$ & $12(80)$ & $62(62)$ \\
\hline Yes & $14(33)$ & $21(55)$ & $0(0)$ & $3(20)$ & $38(38)$ \\
\hline \multicolumn{6}{|c|}{ Asia: mentioned Zika in Southeast Asia } \\
\hline No & $34(79)$ & $26(68)$ & $4(100)$ & $12(80)$ & $76(76)$ \\
\hline Yes & $9(21)$ & $12(32)$ & $0(0)$ & $3(20)$ & $24(24)$ \\
\hline \multicolumn{6}{|c|}{ Pacific: mentioned Zika in Pacific Islands } \\
\hline No & $34(79)$ & $25(66)$ & $4(100)$ & $12(80)$ & $75(75)$ \\
\hline Yes & $9(21)$ & $13(34)$ & $0(0)$ & $3(20)$ & $25(25)$ \\
\hline \multicolumn{6}{|c|}{ Content categories with no entries } \\
\hline No & $43(100)$ & $38(100)$ & $4(100)$ & $15(100)$ & $100(100)$ \\
\hline Yes & $0(0)$ & $0(0)$ & $0(0)$ & $0(0)$ & $0(0)$ \\
\hline
\end{tabular}

Values are presented as number (\%).

'Content categories for which all entries received scores of 'no' (0): US not prepared, aid, medical help, preparedness, cooperation, training, coordination, and danger.

the four created by medical professionals or government public health agencies captured only $1.3 \%$ of total views, while the 43 consumer-generated videos captured $22.4 \%$. In total, these videos were viewed 8894505 times. Compared with the consumer-generated videos, Internet-based news videos (which captured over two-thirds of total views) were more likely to mention the impact of ZIKV on babies and ZIKV cases in Latin America and Africa. In sharp contrast, TV-based news videos, which captured $8.6 \%$ of total views, were more likely to express anxiety or fear of catching ZIKV, to highlight that the public was afraid of ZIKV, and to discuss avoiding pregnancy.

Social media poses both opportunities and challenges in the response to ZIKV. Social media sites are popular sources of health information related to pregnancy and children's health $[14,15]$. The interactive nature of social media and its high penetration in industrialized countries may allow for more effective communication of health information than is feasible through traditional media [16]. In fact, social media interacts with traditional media and amplifies its impact. Previous research found that Ebola-related videos released online by news channels drove up Ebola-related Twitter traffic [11]. Both social media and traditional media can become part of the health communication strategies deployed by public health agencies to achieve greater effects. However, social media also has the potential to amplify unnecessary anxiety during critical time periods of infectious disease outbreaks [17]. Emerging reports of fetal microcephaly, a potential indicator of impaired fetal brain development, in ZIKV-infected pregnant women [2], may cause anxiety and may lead to unnecessary abortions among pregnant women with potential exposure to ZIKV. Our findings indicate that some of the most widely viewed YouTube videos mentioned anxiety and fear associated with 'catching' ZIKV and 
Table 3. ORs of content categories across sources of Englishlanguage ZIKV-related YouTube videos as compared to consumer-generated videos

\begin{tabular}{|c|c|c|}
\hline Content category ${ }^{1,2}$ & OR $(95 \% \mathrm{CI})^{2}$ & $p$-value \\
\hline \multicolumn{3}{|c|}{ Transmission: mentioned how Zika is transmitted } \\
\hline Internet & $2.25(0.63,8.01)$ & 0.21 \\
\hline \multicolumn{3}{|l|}{ Professional $^{2}$} \\
\hline \multicolumn{3}{|l|}{ TV news $^{2}$} \\
\hline \multicolumn{3}{|c|}{ Mosquito: mentioned that Zika is transmitted by mosquitos } \\
\hline Internet & $2.25(0.63,8.01)$ & 0.21 \\
\hline \multicolumn{3}{|l|}{ Professional $^{2}$} \\
\hline \multicolumn{3}{|l|}{ TV news $^{2}$} \\
\hline \multicolumn{3}{|c|}{ Sex: mentioned Zika transmission through male sex partners } \\
\hline Internet & $0.88(0.35,2.18)$ & 0.78 \\
\hline Professional & $0.56(0.05,5.88)$ & 0.63 \\
\hline TV news & $0.61(0.17,2.25)$ & 0.46 \\
\hline \multicolumn{3}{|c|}{$\begin{array}{l}\text { Transfusion: mentioned Zika transmission through } \\
\text { transfusion }\end{array}$} \\
\hline Internet & $0.54(0.048,6.36)$ & 0.64 \\
\hline \multicolumn{3}{|l|}{ Professional $^{2}$} \\
\hline \multicolumn{3}{|l|}{ TV news $^{2}$} \\
\hline \multicolumn{3}{|c|}{ Other: mentioned Zika transmission through other avenues } \\
\hline Internet & $3.11(0.57,17.05)$ & 0.19 \\
\hline \multicolumn{3}{|l|}{ Professional $^{2}$} \\
\hline \multicolumn{3}{|l|}{ TV news $^{2}$} \\
\hline \multicolumn{3}{|c|}{ Baby: mentioned the impact of Zika on babies } \\
\hline Internet & $6.25(1.64,23.76)$ & 0.007 \\
\hline \multicolumn{3}{|l|}{ Professional $^{2}$} \\
\hline \multicolumn{3}{|l|}{ TV news $^{2}$} \\
\hline \multicolumn{3}{|c|}{ Anxiety: mentioned anxiety/fear of catching Zika } \\
\hline Internet & $2.02(0.45,9.09)$ & 0.36 \\
\hline Professional & $4.44(0.35,56.88)$ & 0.25 \\
\hline TV news & $6.67(1.36,32.70)$ & 0.02 \\
\hline \multicolumn{3}{|c|}{ Prevention: mentioned (any) prevention } \\
\hline Internet & $0.47(0.17,1.32)$ & 0.15 \\
\hline \multicolumn{3}{|l|}{ Professional $^{2}$} \\
\hline TV news & $3.11(0.92,10.46)$ & 0.07 \\
\hline \multicolumn{3}{|c|}{ Case: mentioned number of cases } \\
\hline Internet & $2.03(0.60,6.83)$ & 0.25 \\
\hline Professional & $2.53(0.22,29.29)$ & 0.46 \\
\hline TV news & $3.8(0.92,15.75)$ & 0.07 \\
\hline \multicolumn{3}{|c|}{ Latin America: mentioned number of cases in Latin America } \\
\hline Internet & $5.63(1.47,21.52)$ & 0.01 \\
\hline Professional ${ }^{2}$ & & \\
\hline TV news $^{2}$ & & \\
\hline US: mentioned number of ca & & \\
\hline Internet & $0.99(0.32,3.04)$ & 0.98 \\
\hline Professional & $4.38(0.53,35.91)$ & 0.17 \\
\hline TV news & $2.19(0.58,8.19)$ & 0.25 \\
\hline Public fear: highlighted that & & \\
\hline Internet & $0.55(0.05,6.36)$ & 0.64 \\
\hline Professional $^{2}$ & & \\
\hline TV news & $7.45(1.20,46.16)$ & 0.03 \\
\hline Not pregnant: discussed not & & \\
\hline Internet & $2.09(0.83,5.27)$ & 0.12 \\
\hline Professional $^{2}$ & & \\
\hline TV news & $3.88(1.13,13.25)$ & 0.03 \\
\hline
\end{tabular}

Table 3. Continued

\begin{tabular}{|c|c|c|}
\hline Content category ${ }^{1,2}$ & OR $(95 \% \mathrm{CI})^{2}$ & $p$-value \\
\hline \multicolumn{3}{|c|}{ US cases: highlighted cases in the US } \\
\hline Internet & $1.14(0.15,8.50)$ & 0.90 \\
\hline Professional & $20.50(1.82,230.51)$ & 0.01 \\
\hline TV news & $5.12(0.77,34.31)$ & 0.09 \\
\hline \multicolumn{3}{|c|}{ Olympics: discussed the 2016 Olympics in Brazil } \\
\hline Internet & $2.03(0.60,6.83)$ & 0.26 \\
\hline \multicolumn{3}{|l|}{ Professional $^{2}$} \\
\hline TV news & $1.17(0.20,6.77)$ & 0.86 \\
\hline \multicolumn{3}{|c|}{$\begin{array}{l}\text { Hoax: mentioned that people felt that Zika is a hoax, } \\
\text { there is no such thing, or cases are staged }\end{array}$} \\
\hline Internet & $2.02(0.45,9.09)$ & 0.36 \\
\hline \multicolumn{3}{|l|}{ Professional $^{2}$} \\
\hline \multicolumn{3}{|l|}{ TV news ${ }^{2}$} \\
\hline \multicolumn{3}{|c|}{$\begin{array}{l}\text { Conspiracy: mentioned Zika as being intentional, } \\
\text { population control, conspiracy theory, etc. }\end{array}$} \\
\hline Internet & $1.05(0.40,2.77)$ & 0.92 \\
\hline \multicolumn{3}{|l|}{ Professional $^{2}$} \\
\hline \multicolumn{3}{|l|}{ TV news ${ }^{2}$} \\
\hline \multicolumn{3}{|c|}{ Africa: mentioned Zika in Africa } \\
\hline Internet & $2.56(1.04,6.31)$ & 0.04 \\
\hline \multicolumn{3}{|l|}{ Professional $^{2}$} \\
\hline TV news & $0.52(0.13,2.14)$ & 0.36 \\
\hline \multicolumn{3}{|c|}{ Asia: mentioned Zika in Southeast Asia } \\
\hline Internet & $1.74(0.64,4.76)$ & 0.28 \\
\hline \multicolumn{3}{|l|}{ Professional $^{2}$} \\
\hline TV news & $9.44(0.22,4.08)$ & 0.94 \\
\hline \multicolumn{3}{|c|}{ Pacific: mentioned Zika in Pacific Islands } \\
\hline Internet & $1.96(0.73,5.31)$ & 0.18 \\
\hline \multicolumn{3}{|l|}{ Professional $^{2}$} \\
\hline TV news & $0.94(0.22,4.08)$ & 0.94 \\
\hline
\end{tabular}

$\mathrm{OR}$, odds ratio; $\mathrm{Cl}$, confidence interval; ZIKV, Zika virus.

'The category of consumer videos was used as the reference category for the other three categories of sources of YouTube videos (Internet-based news, professional, and TV news).

${ }^{2}$ If all videos belong to a particular category of source of video, then we cannot calculate the $\mathrm{OR}$ and the standard error will not be meaningful. We omitted the content category of 'treatment,' as there was only 1 Internet-based news video that mentioned treatment, and no meaningful OR could be calculated. Likewise, we omitted the content categories of 'comedy' and 'prank' as there was only 1 consumer video that contained such content.

included discussions about avoiding pregnancy due to the potential risk of ZIKV infection during pregnancy. While they may be legitimate TV news reports, the extended coverage on this uncertain risk and exaggerated anxiety may lead to adverse effects on public health, because witnessing others' fear may actually induce anxiety in oneself and lead to misinformed pregnancy decisions [18], as well as stress during pregnancy, which would be detrimental to the health of both pregnant women and their fetuses. While reading about others' personal health experience on social media may enhance feelings of identification, social support, and in some cases, may improve health lit- 
eracy about ZIKV, distinguishing accurate information from misinformation or communications that evoke excessive fear remains a challenge. Little is known about how these YouTube videos may affect users' mental health or health-related behaviors, and these topics warrant further research.

Engaging non-professional users is critical to developing ZIKV-related health communication that is not only accurate but actually reaches its intended audience. A top-down and "knowledge-deficient" model of health communications during crisis situations remains pervasive among public health practitioners [19], wherein the general public is assumed to be "deficient" in understanding essential health knowledge and making informed risk-related decisions, while health communicators known to be sufficiently knowledgeable aim to fill the information "gap." This view was challenged by Hulme [20], who argued that risk communications must involve both nonexperts and experts and that there should be two-way interactions. The development of social media further reinforces a discussion-based environment in which a mixture of professional- and layman-led health information is present. Therefore, health communicators should establish a better understanding of widely viewed social media posts and videos generated by consumers, and the rationale upon which those choices are based. This will help inform the health authorities responsible for developing a public engagement policy and will facilitate embracing bidirectional communication.

This study had a cross-sectional design, and we did not obtain longitudinal data on how the number of views of YouTube videos changed over time. We limited our study to Englishlanguage videos. Spanish and Portuguese videos will be an interesting subject for future studies. We did not have data on the viewers. We did not evaluate the production or scientific quality of the videos. These analyses were beyond the scope for this paper and will be fruitful directions for future research.

To conclude, we observed statistically significant differences in informational content between consumer-generated ZIKVrelated videos and videos from other sources. Public health agencies should consider establishing a larger presence on YouTube to reach more people with evidence-based information about ZIKV.

\section{ACKNOWLEDGEMENTS}

ICHF and ZTHT received salary support from the Centers for Disease Control and Prevention (CDC) (15IPA1509134 and
16IPA1619505). This paper is not related to their CDC-funded projects. This paper does not represent the official positions of the CDC or the United States government.

\section{CONFLICT OF INTEREST}

The authors have no conflicts of interest associated with the material presented in this paper.

\section{ORCID}

Corey H. Basch http://orcid.org/0000-0003-4862-4229

Isaac Chun-Hai Fung http://orcid.org/0000-0001-5496-2529

Rodney N. Hammond http://orcid.org/0000-0002-6655-3156

Elizabeth B. Blankenship http://orcid.org/0000-0003-3650-5441

Zion Tsz Ho Tse http://orcid.org/0000-0001-9741-1137

King-Wa Fu http://orcid.org/0000-0001-8157-5276

Patrick Ip http://orcid.org/0000-0002-6797-6898

Charles E. Basch http://orcid.org/0000-0001-8022-0959

\section{REFERENCES}

1. Rasmussen SA, Jamieson DJ, Honein MA, Petersen LR. Zika virus and birth defects--reviewing the evidence for causality. N Engl J Med 2016;374(20):1981-1987.

2. European Centre for Disease Prevention and Control. Rapid risk assessment: Zika virus disease epidemic; 2016 [cited 2016 Jun 21]. Available from: http://ecdc.europa.eu/en/publications/Publications/zika\%20virus\%20rapid\%20risk\%20assessment\%2010-05-2016.pdf.

3. Fung IC, Duke CH, Finch KC, Snook KR, Tseng PL, Hernandez AC, et al. Ebola virus disease and social media: a systematic review. Am J Infect Control 2016;44(12):1660-1671.

4. Glowacki EM, Lazard AJ, Wilcox GB, Mackert M, Bernhardt JM. Identifying the public's concerns and the Centers for Disease Control and Prevention's reactions during a health crisis: an analysis of a Zika live Twitter chat. Am J Infect Control 2016; 44(12):1709-1711.

5. Fu KW, Liang H, Saroha N, Tse ZT, Ip P, Fung IC. How people react to Zika virus outbreaks on Twitter? A computational content analysis. Am J Infect Control 2016;44(12):1700-1702.

6. Southwell BG, Dolina S, Jimenez-Magdaleno K, Squiers LB, Kelly BJ. Zika virus-related news coverage and online behavior, United States, Guatemala, and Brazil. Emerg Infect Dis 2016;22(7):1320-1321. 
7. Sharma M, Yadav K, Yadav N, Ferdinand KC. Zika virus pandemic-analysis of Facebook as a social media health information platform. Am J Infect Control 2017;45(3):301-302.

8. Houts PS, Doak CC, Doak LG, Loscalzo MJ. The role of pictures in improving health communication: a review of research on attention, comprehension, recall, and adherence. Patient Educ Couns 2006;61(2):173-190.

9. Statista. Statistics and facts about YouTube; 2016 [2016 Jun 21]. Available from: http://www.statista.com/topics/2019/ youtube/.

10. Basch CH, Basch CE, Ruggles KV, Hammond R. Coverage of the Ebola virus disease epidemic on YouTube. Disaster Med Public Health Prep 2015;9(5):531-535.

11. Towers S, Afzal S, Bernal G, Bliss N, Brown S, Espinoza B, et al. Mass media and the contagion of fear: the case of Ebola in America. PLoS One 2015;10(6):e0129179.

12. Pathak R, Poudel DR, Karmacharya P, Pathak A, Aryal MR, Mahmood $\mathrm{M}$, et al. YouTube as a source of information on Ebola virus disease. N Am J Med Sci 2015;7(7):306-309.

13. Centers for Disease Control and Prevention. Zika virus; 2016 [cited 2016 Jun 21]. Available from: http://www.cdc.gov/zika/.

14. Bernhardt JM, Felter EM. Online pediatric information seeking among mothers of young children: results from a qualitative study using focus groups. J Med Internet Res 2004;6(1):e7.

15. Wong WH, Li SL, Fu KW, Tinsley H, Chow CB, Ip P. The importance of online resources for parents of children with special needs in Hong Kong: south China's experience. J Health Med Inform 2015;6:192.

16. Moorhead SA, Hazlett DE, Harrison L, Carroll JK, Irwin A, Hoving $C$. A new dimension of health care: systematic review of the uses, benefits, and limitations of social media for health communication. J Med Internet Res 2013;15(4):e85.

17. Fung IC, Tse ZT, Cheung CN, Miu AS, Fu KW. Ebola and the social media. Lancet 2014;384(9961):2207.

18. Bandura A. Self-efficacy: toward a unifying theory of behavioral change. Psychol Rev 1977;84(2):191-215.

19. Ziman J. Not knowing, needing to know, and wanting to know. In: Lewenstein $B$, editor. When science meets the public. Washington, DC: American Association for the Advancement of Science; 1992, p. 13-20.

20. Hulme M. Why we disagree about climate change: understanding controversy, inaction and opportunity. Cambridge: Cambridge University Press; 2009, p. 217-221. 